\title{
Performance Analysis for Gun Firing Impact Simulator Based on Hydraulic Motor
}

\author{
Chi He* , Guangling Dong, Qiang Li, Mingyue Sun and Zhiqiang Wei \\ Department of Test Technology Baicheng Ordnance Test Center, 137001, Baicheng Jilin, China \\ ${ }^{*}$ Corresponding author
}

\begin{abstract}
In order to save development expenditure, shorten test cycle and improve quality, modelling and simulation (M\&S) is used in processes as index demonstration, developmental design, and type approval test. The main applications of gun and simulation technologies in its type approval test are introduced in this paper. Besides, technical indexes, system composition, and working principle of gun firing impact simulator based on hydraulic motor are introduced, conversion coefficient between firing impact torque and simulated impact torque is calculated. Finally, performances of gun firing impact simulator are verified with live test, whose results indicate that the simulator meets the requirements of design specifications.
\end{abstract}

Keywords-hydraulic motor; firing impact; simulator; performance analysis

\section{INTRODUCTION}

By now, simulation technology is widely used in artillery research and development region both at home and abroad. According to relevant information, in late 1970s and early 1980s, Rock Island Arsenal of US has developed a fixed gunpowder simulation test bed for acceptance testing of the carriage and the recoil mechanisms. Aviatentas Corporation of Rheinmetall Group in West German also developed an artillery dynamic test stand for Deutscher forces [1].

At present, many engineers and experts have attached great importance to the research and application of M\&S technology on gun firing dynamics and have achieved some phase achievements. For example, Professor Xiaoting Rui from Nanjing University of Science and Technology conducted a modeling and simulation of naval launch dynamics methodological research [2], Honghao Zhang and Dr. Di carried out numerical simulation and analysis study on artillery recoil movement [3] and muzzle impact recoil motion [4]. All the above researches are mainly used in weapon system demonstration and research stage, which generally adopt numerical simulation technology to study gun firing impact and its influence on the artillery system. Design of gun firing impact simulation test system and the related technologies carried out by Ting Gao from Baicheng Ordnance Test Center of China [5], and Dr. Lang [6] used electro-hydraulic technology and methods to drive accelerated mass hit against artillery muzzle, which could generate simulated gun firing impact effect.

In this paper, the influence of gun live firing on weapon system is simulated through electro-hydraulic technology to exert impact torque on driving motor shaft of servo system, where hydraulic motor is taken as load components. The system used in approval test of gun servo system, which can complete items as environmental adaptability test, reliability test and firing test to check whether the servo system meets the requirements of tactical and technical indicators. The system performance is testified based on analysis and calculation of firing impact torque.

\section{SySTEM COMPOSITION AND WORKING PRINCIPLE}

\section{A. Main Technical Specifications}

(1) Firing torque. Frequency: $0 \mathrm{~Hz} \sim 1.0 \mathrm{~Hz}$, moment range: $0 \mathrm{Nm} \sim 40 \mathrm{Nm}$; Frequency: $1.0 \mathrm{~Hz} \sim 10 \mathrm{~Hz}$, torque range: $0 \mathrm{Nm}$ $\sim 20 \mathrm{Nm}$; Precision: $\pm 10 \%$ FS.

(2) Firing impact frequency. Range: $0 \mathrm{~Hz} \sim 10 \mathrm{~Hz}$, Precision: $\pm 1 \mathrm{~Hz}$.

(3) Operating temperature requirements. $0^{\circ} \mathrm{C} \sim 40^{\circ} \mathrm{C}$ for computer, $-40^{\circ} \mathrm{C} \sim 50^{\circ} \mathrm{C}$ for others; Storage temperature: $-50^{\circ} \mathrm{C} \sim 60^{\circ} \mathrm{C}$.

(4) Power Requirements. Voltage: $380 V \pm 10 \%$; Frequency: $50 \mathrm{~Hz} \pm 1 \mathrm{~Hz}$

\section{B. System Composition}

Gun firing impact simulator is mainly used in type approval test of gun servo system to replace the effect of live firing with simulated impact moment load. Closed-loop control technology of electro-hydraulic servo is adopted by the simulator, which takes double-acting hydraulic motor as load torque simulation unit and forms closed-loop control together with the control and measurement system. Thus, it has the characteristics of high precision, high frequency response, stable operation and compact host structure.

Block diagram of gun firing impact simulator is shown in Figure I. 


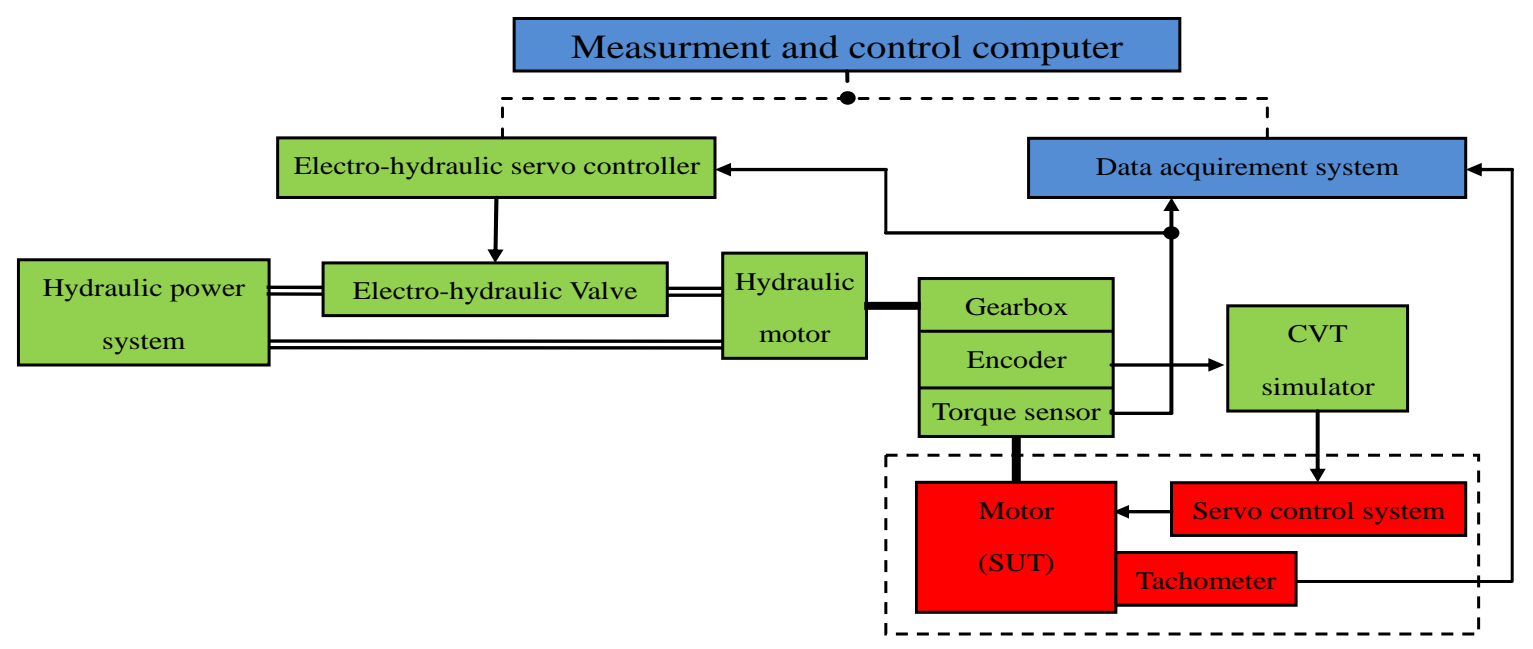

FIGURE I. BLOCK DIAGRAM OF GUN FIRING IMPACT SIMULATOR

The system is composed of two parts, one is gun servo system under test (SUT- dashed box in the figure), including the tested motor, servo control box, power amplifier, etc. The other is gun firing impact simulator, including 6 subsystems as movable workbench, hydraulic servo system, hydraulic power system, transmission ratio analog system, computer control system and software system. Dotted line in the figure indicates CAN bus connection; Double solid line is hydraulic pipe connection; Bold solid lines indicate mechanical connection.

Figure II is the design sketch of gun firing impact simulator, and Figure III is its real photo.

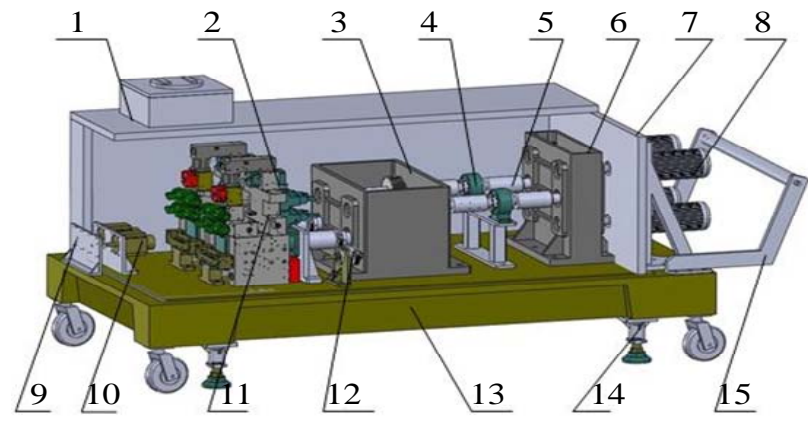

FIGURE II. GUN FIRING IMPACT SIMULATOR RENDERING

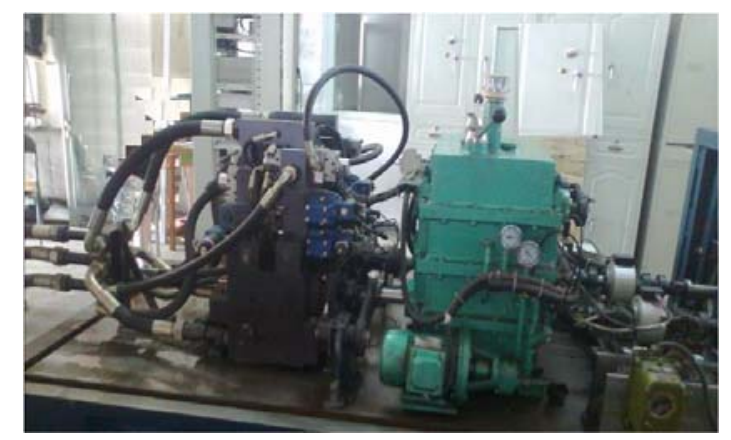

FIGURE III. GUN FIRING IMPACT SIMULATOR PHOTOGRAPH
The simulator consists of 15 basic parts: 1. Temperature controller; 2. Hydraulic servo system; 3. Gearbox; 4. Torque sensor; 5. Coupling; 6. Combo gearbox; 7. Support frame of motor in test; 8 . Motors under test; 9 . Mounting rack of receiver; 10. AC servo motor for transmission ratio simulation; 11. Current configuration socket; 12. Encoder; 13. High stiffness platform; 14. Foot; 15. Handle.

\section{Working Principle}

When the required firing torque on hydraulic load simulation element at hydraulic motor input shaft is calculated, the computer sends a directive to the servo controller to control high-frequency electro-hydraulic servo valve. Then, electro-hydraulic servo valve controls pressure and flow on both import and export to realize torque control of hydraulic motor. Thus, load simulation task is accomplished.

The electro-hydraulic servo closed-loop control technology with torque control mode is adopted by control system. Each channel has a closed-loop control, where control signal is generated by error signal between signal source directives and feedback signal. The error signal is transmitted to driver of servo valve after PID-regulation, which controls servo valve to drive hydraulic load simulation system. In this way, torque action simulation following the given command is realized. The control process is that the regulator continuously adjusts the output of the driver to minimize the error between the output signal and the given signal to complete the system closed-loop servo control.

The hydraulic load simulation system uses a serial connected double hydraulic motor as the load simulation actuator. Two hydraulic motors can be used alone or in combination according to different test requirements. Each hydraulic motor is equipped with a pressure sensor for measuring the outlet pressure. Where, the low-power hydraulic motors can simulate the high-frequency, low-torque impact load, and high-power hydraulic motors can simulate low-frequency, high torque impact load. 


\section{CALCULATION AND ANALYSIS OF FIRING IMPACT TORQUE}

Before type approval test of gun servo system, design values of firing impact torque need to be given. Two ways are usually used, one is to give artillery firing torque; the other is to give artillery recoil resistance.

Given the gun firing torque, the moment that the gun firing impact simulator needs to simulate can be calculated according to Eq. 1.

$$
M_{\text {motor }}=M_{\text {gun }} \times \eta / i \text {. }
$$

In Eq. 1, $M_{\text {motor }}$ is the firing torque converted to the motor shaft of servo system; $M_{\text {gun }}$ is real gun firing torque; $i$ is transmission ratio of gun; $\eta$ is transmission efficiency.

As example, the above three parameters for an anti-aircraft gun are: $M_{\text {gun }}=0 \sim 20 \times 10^{3} \mathrm{Nm}, i=590, \eta=0.58$, actual torque exerted on motor shaft $M_{\text {motor }}$ can be calculated from Eq. 1 as $19.66 \mathrm{Nm}$.

If recoil resistance of the gun is given, the moment that the gun firing impact simulator needs to simulate can be calculated according to Eq. 2.

$$
M_{\text {motor }}=\left(M_{1}+M_{2}+M_{3}\right) \times \eta / i .
$$

In Eq. 1, $M_{1}$ indicates the friction torque generated by vertical component of recoil resistance on raceway; $M_{2}$ is the friction torque generated by reaction force of raceway to horizontal component of recoil resistance; $M_{3}$ is torque caused by recoil resistance of gun due to mismatch between rotary center and barrel axis or symmetry axis; $i$ is transmission ratio of gun; $\eta$ is transmission efficiency. $M_{1}, M_{2}, M_{3}$ are calculated from Eq. 3, Eq. 4 and Eq. 5.

$$
\begin{aligned}
& M_{1}=K R_{m} \sin \alpha \times k_{f} . \\
& M_{2}=K R_{m} \cos \alpha \times k_{f} . \\
& M_{3}=R_{m} \cos \alpha \times l .
\end{aligned}
$$

In above equations, $K$ indicates barrel number in simultaneous firing; $R_{m}$ is the largest recoil resistance; $\alpha$ is elevation angle; $k_{f}$ is the friction coefficient; $l$ is the distance between rotary center and single shooting barrel axis, or the distance between rotary center and symmetry axis of the two shooting barrels.

For example, the above parameters for certain type of large caliber gun are: $R_{m}=180 \mathrm{kN}, \alpha=45^{\circ}, k_{f}=0.01 \mathrm{~m}, l=0.44 \mathrm{~m}, i=933$, $\eta=0.58$. Actual torque exerted on motor shaft Mmotor can be calculated from Eq. 1 as $37.98 \mathrm{Nm}$.

\section{PERFORMANCE VERIFICATION TESTS}

\section{A. Test System and Experimental Design}

Gun firing impact simulator includes elevation system and azimuth system, and each system can achieve firing impact load from 2 motors. In order to verify the precision of simulator on firing impact torque and shooting frequency, two sets of three-phase asynchronous motors were selected as dummy loads in the tests, whose models are as follows: $116 \mathrm{M}-2 / 2.2 \mathrm{kw} / 50 \mathrm{~Hz}$.

The verification test is carried out simultaneously both on elevation system and azimuth system. Rotation directions of the motors is forward clockwise and counterclockwise. The loading torques are both static resistance torques with parameters of $0 \mathrm{Nm}, 2 \mathrm{Nm}$, and firing impact torques with parameters of $5 \mathrm{Nm}$, $10 \mathrm{Nm}, 20 \mathrm{Nm}$ and $40 \mathrm{Nm}$. The shooting frequencies are $0.5 \mathrm{~Hz}$, $1 \mathrm{~Hz}, 4 \mathrm{~Hz}, 8 \mathrm{~Hz}$ and $10 \mathrm{~Hz}$.

\section{B. Test Data Analysis}

Two groups of test data from elevation system are selected for analysis. The first group takes on parameters of forward and reverse loading, firing impact torque $20 \mathrm{Nm}$, static resistance torque $2 \mathrm{Nm}$, shooting frequency $1 \mathrm{~Hz}$, and projectile number 16 . The second group takes on parameters of forward and reverse loading, reverse firing impact torque $20 \mathrm{Nm}$, static resistance torque $0 \mathrm{Nm}$, forward firing impact torque $10 \mathrm{Nm}$, static resistance torque $2 \mathrm{Nm}$, shooting frequency $4 \mathrm{~Hz}$, and shooting time on reverse direction 20s, forward direction 10s. The test data is shown in Table I.

In Table I, "-" indicates loaded data in reverse rotation, and "+" indicates loaded data in forward rotation. The load data of

\begin{tabular}{|c|c|c|c|c|c|c|c|c|c|}
\hline \multicolumn{2}{|c|}{ Group No. } & \multicolumn{8}{|c|}{ Firing Impact Torque [Nm] } \\
\hline \multirow{4}{*}{1} & \multirow[b]{2}{*}{ - } & -27.18 & -22.32 & -22.21 & -22.63 & -22.97 & -23.00 & -22.89 & -22.93 \\
\hline & & -22.78 & -22.80 & -22.79 & -22.79 & -22.64 & -22.63 & -15.48 & -14.55 \\
\hline & \multirow{2}{*}{+} & 23.98 & 23.89 & 23.67 & 23.70 & 23.63 & 23.72 & 23.69 & 23.59 \\
\hline & & 23.59 & 23.67 & 23.68 & 23.64 & 23.62 & 23.57 & 23.65 & 23.68 \\
\hline \multirow{4}{*}{2} & \multirow{2}{*}{-} & -20.98 & -20.63 & -20.68 & -20.87 & -21.62 & -20.06 & -20.61 & -20.31 \\
\hline & & -20.30 & -20.09 & -20.63 & -20.87 & -21.87 & -21.05 & -20.61 & -20.30 \\
\hline & \multirow{2}{*}{+} & 12.034 & 11.20 & 11.22 & 11.32 & 11.39 & 11.72 & 10.99 & 12.18 \\
\hline & & 11.198 & 12.14 & 12.38 & 12.40 & 11.86 & 12.37 & 12.07 & 11.59 \\
\hline
\end{tabular}
second group start from 5 s on reverse operation, and from 30s on forward operation, where a maximum value is collected per second.

TABLE I. SIMULATION TEST DATA OF FIRING IMPACT TORQUE 
Figure IV and Figure V show loading curve of firing impact torque for the first and the second group respectively.

It can be seen from Table I and Fig. 4 that the first group of shooting simulation data on reverse running has three over-tolerance, namely $-27.18 \mathrm{Nm},-15.48 \mathrm{Nm}$ and $-14.55 \mathrm{Nm}$, and the relative error of the maximum tolerance is (-20.0$(-14.55+2.0)) /-20.0 \times 100 \%=37.25 \%$. All other 13 samples

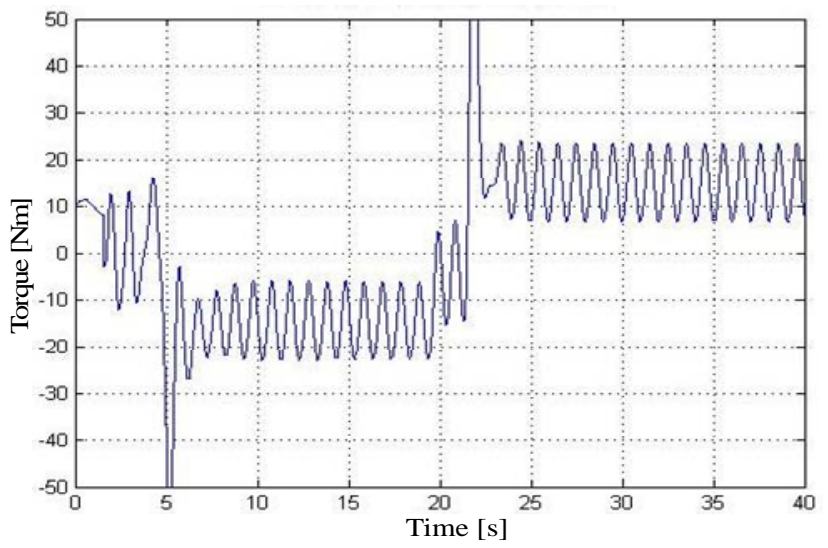

FIGURE IV. GROUP NO. 1 CURVE OF FIRING IMPACT TORQUE

In the three-out-of-tolerance data, the first data occurs at the loading start stage, the fifteenth and the sixteenth data occur at motor reversing stage of gun servo system. These two stages have the same characteristic that the system inertial torque plays a leading role, while the firing impact torque contains part of inertia torque.

Table 1 and Figure V show that firing impact torques on both forward and reverse running meet the requirements of specifications. The maximum error is $1.87 \mathrm{Nm}$, maximum relative error is $9.3 \%$ in reverse running, and maximum error is $1.40 \mathrm{Nm}$, maximum relative error is $7.0 \%$ in forward running.

\section{SUMMARY}

Gun firing impact simulator is designed as an automatic measurement control system based on hydraulic motor to simulate the impact effect of gun live firing with modeling and simulation methods. The following conclusions can be drawn through the research:

(1) The impact torque generated by gun live firing can be simulated using hydraulic motor as load of gun servo system;

(2) During the simulation process of firing impact torque, the influence of system inertia torque and static resistance torque on simulation accuracy should also be considered;

(3) Gun firing impact simulator can simulate the firing impact torque of large caliber $(100 \mathrm{~mm})$ gun, which satisfies test requirements with shooting frequency up to 600 rounds / min;

(4) The research and verification results show that gun firing impact simulator is scientific and feasible, with good operability. satisfy the precision requirement of $10 \%$, where the maximum relative error is $(-20.0-(-22.93+2.0)) /-20.0 \times 100 \%=-4.65 \%$. The first group of shooting simulation data on forward running meet the precision requirements, of which the maximum relative error is $(20.0-(23.98-2.0)) / 20.0 \times 100 \%=-9.9 \%$. Shooting frequency is $1 \mathrm{~Hz}$ (10 impacts in 10s), meeting the system design specifications.

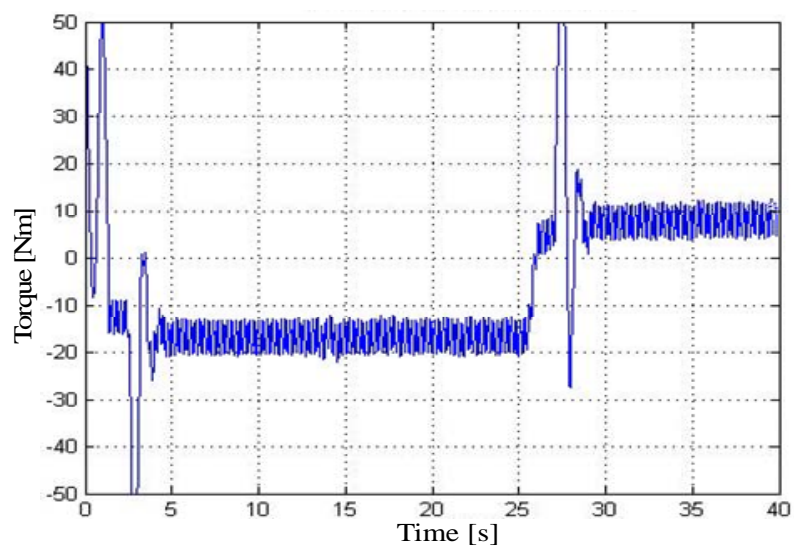

FIGURE V. GROUP NO. 2 CURVE OF FIRING IMPACT TORQUE

\section{REFERENCES}

[1] Y.W. Yao, Simulation Test System of Gun Recoil and Numerical Calculations, ACTA ARMAMENT ARII , 22(2001) 152-155.

[2] B. He, X.T. Rui, Y.Q. Lu and H.L. Yu, A Blocking Method for Lunching Dynamics of Shipboard Gun, Journal of Dynamics and Control, 2 (2004) 34-37.

[3] H.H. Zhang, Y.C. Chen, R.L Wang and Y.G. Xiong, Reserch on the Numerical Value Simulation of Gun- Power- Recoil. Journal of Ordnance Engineering College, 12(2000) 12-16.

[4] C.C. Di, L. Liu, J. Zheng and Y.C. Chen, Numerical Simulation on Dynamic Recoil Test with Gun Muzzle Subjected to High-velocity Impact, Explosion and Shock Waves, 32(2012) 323-327.

[5] T. Gao, C. He, Z.J. Fan and H.L. Guo, Analysis and evaluation of artillery fire simulation test, Key Engineering Materials, 620(2014) 632-637.

[6] F.Y. Lang and W.J. Li, Design of a Large Caliber Self-Propelled Gun Shooting Simulation device, Gun Launch and Control Journal, 3(2012) $52-54$ 